\title{
Early abdominal closure using component separation in patients with an open abdomen after trauma: a pilot study
}

This article was published in the following Dove Press journal:

Open Access Surgery

24 February 2015

Number of times this article has been viewed

\author{
Karan Chopra' \\ Kashyap Komarraju \\ Tadisina' \\ Jamil A Matthews' \\ Jennifer Sabino' \\ Devinder P Singh' \\ Wassim Habre ${ }^{2}$ \\ 'University of Maryland Medical \\ Center, Baltimore, MD, ${ }^{2}$ Crozer- \\ Chester Medical Center, Upland, \\ PA, USA
}

Correspondence: Wassim Habre Crozer-Chester Medical Center, Vivacqua Pavillion Suite 440,

I Medical Center Boulevard, Upland, PA 19013, USA

$\mathrm{Tel}+\mathrm{I} 6104477605$

$\mathrm{Fax}+16106198523$

Email wassim.habre@crozer.org
Background: Permanent abdominal wall closure in patients undergoing damage-control laparotomy is achieved using techniques involving separation and advancement of abdominal wall components along with surgical mesh. However, these techniques are costly, morbid, and time-consuming. We compared outcomes following permanent abdominal closure using component separation (CS) with non-cross-linked porcine acellular dermal matrix (PADM) versus temporizing split-thickness skin graft (STSG) closure.

Materials and methods: A retrospective review identified eleven patients who underwent damage-control laparotomies from January 2010 to June 2011. Outcomes assessed included hospital length of stay (LOS), days on ventilator, size of defect and tissue matrix, and postoperative functionality.

Results: Of the eleven patients identified, primary closure was achieved in five, CS/PADM closure in four, and STSG closure in two. Those with primary closure were excluded from the study. In the CS/PADM group, large defects $(>24 \times 20 \mathrm{~cm})$ were successfully closed using CS with PADM. Patients in the CS/PADM group had reduced third-space fluid loss, less difficulty in managing the open abdominal wound, and decreased risks for potential enterocutaneous fistulae, and intra-abdominal abscess formation. Total hospital LOS and days on the ventilator were also significantly reduced in the CS/PADM group compared with the STSG group.

Conclusion: Early abdominal closure using CS/PADM was safe and effective in these patients, and may be cost-effective because only one operation is required. The shorter hospital LOS and days on the ventilator observed versus STSG closure appear promising, although further study is required.

Keywords: acellular dermal matrix, laparotomy, abdominal wall closure, split-thickness skin graft, Strattice

\section{Introduction}

Damage-control laparotomy (DCL) is a widely accepted technique for the management of patients with life-threatening traumatic injuries and abdominal sepsis. ${ }^{1-4}$ DCL is a multiple-stage procedure designed to provide rapid hemostasis, control contamination, allow rapid resuscitation, and avoid abdominal compartment syndrome. To achieve this, the abdominal fascia is left open, with plans for a second-look operation in which packs are removed, missed injuries are identified, and definitive repairs are made. If possible, a tension-free fascial closure is then performed. . $^{3,4}$

However, closure within 2 weeks after the initial injury cannot be achieved in a small population of patients. These patients will undergo temporary nonfascial closure followed by delayed, definitive fascial closure when clinically achievable, 6-12 
months later. ${ }^{5}$ This temporizing measure of nonfascial closure is performed to minimize fluid losses, prevent bowel desiccation, and prevent infection with the goal of permanently reconstructing the abdominal wall at a later date. ${ }^{6-9}$ Current techniques to achieve permanent coverage and restoration of the abdominal domain include component separation (CS) and a variety of biologic and permanent mesh. However, these strategies have several disadvantages, as they are costly and involve multiple trips to the operating room, loss of abdominal domain, and large abdominal defect-associated comorbidities. These challenges result in greater patient discomfort, decreased patient quality of life, and additional costs. $^{10-12}$

Strattice $^{\mathrm{TM}}$ Reconstructive Tissue Matrix (LifeCell, Branchburg, NJ, USA) is an intact, non-cross-linked porcine acellular dermal matrix (PADM) that was designed as a surgical mesh for soft-tissue repair; it presents a tissue scaffold for repopulation and recellularization, and it facilitates tissue ingrowth and incorporation. Previously, it has been reported that the use of Strattice in the repair of contaminated ventral incisional hernias in high-risk patients allowed for successful reconstruction of the abdominal defect in patients followed for 2 years after repair. ${ }^{13}$

In an attempt to improve the outcomes of patients who require DCL and reduce the number of days from initial surgery to fascial closure, we sought to determine the utility of early ( 2 weeks) abdominal closure using CS reinforced with non-cross-linked PADM in patients following DCL. We hypothesized that early permanent abdominal wall closure is achievable using CS reinforced with non-cross-linked PADM (Strattice). In this pilot study, we present our institution's experience with permanent abdominal closure using CS reinforced with a non-cross-linked PADM following DCL for high-risk patients with trauma injuries.

\section{Materials and methods}

A single-center retrospective review was conducted that included all patients who underwent DCL between January 2010 and June 2011. We compared the outcomes between patients who underwent closure by CS reinforced with the non-cross-linked PADM (CS group) and those patients with split-thickness skin graft (STSG) closure (STSG group). Early closure was defined as permanent closure within 2 weeks of the original surgery. Patients from both the CS and STSG groups were managed initially with wound vacuum-assisted closure (VAC) dressing (ABThera ${ }^{\text {TM}}$; San Antonio, TX, USA) at $125 \mathrm{mmHg}$. Subsequently, for patients in the STSG group, skin grafting was performed as described previously. ${ }^{9,10}$ Patients in the CS group, when clinically stable, were taken to the operating room for abdominal closure. The VAC dressing was removed, and adhesions were taken down.

For those patients who required a feeding tube (three in the CS group), this was placed prior to definitive closure or during the final procedure. The feeding tube was placed as far away superiorly and posteriorly as possible from the intended surgical site. Dissection and flap creation were performed to ensure that this did not communicate with the exit site of the feeding tube. The stomach was anchored to the abdominal wall with silk sutures.

Seprafilm $^{\circledR}$ (Genzyme, Cambridge, MA, USA) was then placed in two of the four CS-group patients at the surgeon's discretion. During surgery, every attempt was made to preserve the perforators at the level of the umbilicus. This was done by preserving the subcutaneous tissue around the umbilicus in a semicircular fashion (Figure 1) and creating a tunnel (Figure 2) immediately lateral to the linea semilunaris. The external oblique aponeurosis was divided $2-3 \mathrm{~cm}$ laterally to the linea semilunaris from the superior iliac spine, up to a distance of approximately $5 \mathrm{~cm}$ above the costal margin bilaterally. To permit optimal medial advancement of the rectus abdominis, the posterior rectus sheath was divided from the costal margin down to the inguinal ligament, approximately $1-2 \mathrm{~cm}$ lateral from the midline.

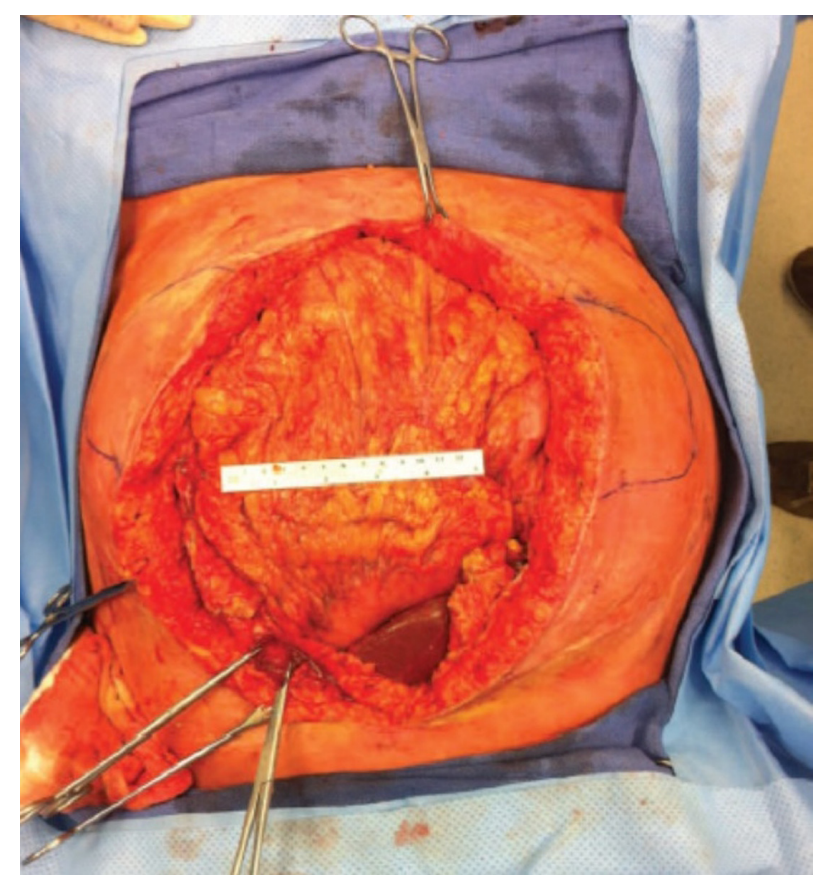

Figure I Component separation. To maintain the perforators at the level of the umbilicus, the subcutaneous tissue was preserved around the umbilicus in a semicircular fashion. 


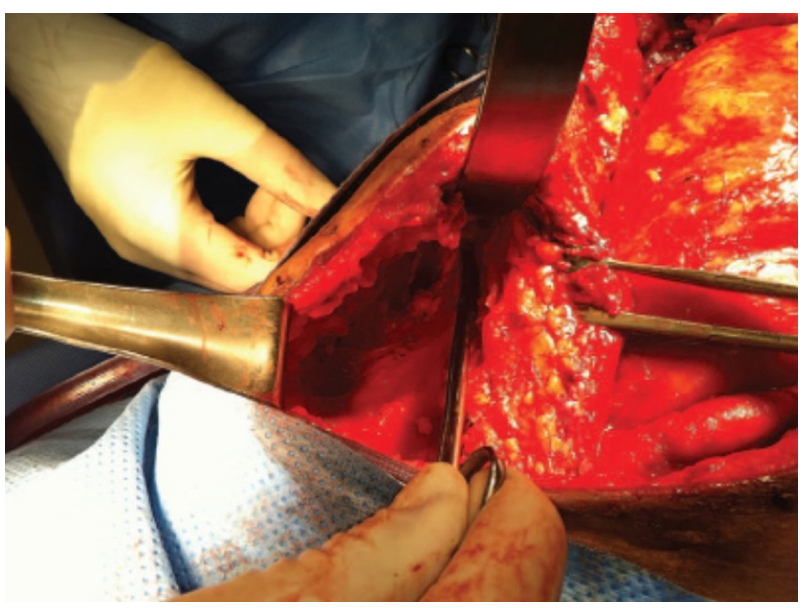

Figure 2 Component separation. To preserve the perforators at the level of the umbilicus, a tunnel was created immediately laterally to the linea semilunaris.

A large piece of non-cross-linked PADM $(20 \times 25 \mathrm{~cm})$ was used in all cases. The tissue matrix was secured to the abdominal wall lateral to the lateral edge of the external oblique aponeurosis with number 2.0 polydioxanone sutures in an onlay fashion. Multiple Jackson-Pratt ${ }^{\circledR}$ drains were placed until drainage decreased to less than $30 \mathrm{cc}$ for at least 48 hours. Peak inspiratory pressure was measured during and after closure, while bladder pressure was measured only if clinically indicated. The patients were artificially paralyzed for the first 24 hours following surgery. The patients' medical records were reviewed for size of defect, adverse outcomes (such as enterocutaneous fistulas and abdominal compartment syndrome), total length of stay (LOS) in hospital, number of days spent in the intensive care unit, number of days on a ventilator, Injury Severity Score, and functionality on follow-up. The results were summarized using descriptive statistics and compared between the CS and STSG groups. No further statistical analysis was performed, due to limited sample size ( $n=2$ versus $n=4$ ).

\section{Results}

During the study period, a total of eleven trauma-surgery patients required DCL (Table 1). Five patients received early primary fascia-to-fascia closure, and one of these patients died; all of these patients were excluded from the study, and their characteristics are shown in Table 2.

The study group consisted of the six patients who underwent DCL who were not candidates for primary fascia-to-fascia closure (Table 2). Four patients underwent early abdominal closure using CS reinforced with the non-cross-linked PADM. Of the patients in this group, three had suffered blunt injury trauma and one had a penetrating injury. Two patients underwent temporary abdominal closure with STSG: one patient had suffered blunt injury trauma, and one had a penetrating injury. All patients underwent closure within 2 weeks, with an average of closure within $10 \pm 2.8$ days.

In the CS group, the average size of the defect was large $(24 \times 20 \mathrm{~cm})$, and defects were successfully closed using CS reinforced with the non-cross-linked PADM (Figure 3). The CS $(n=4)$ and STSG $(n=2)$ groups had similar average Injury Severity Scores of 31 and 34. The average total hospital LOS was lower in the CS group (31 days) compared to the STSG group (72 days, Table 2). Additionally, the number of days on the ventilator was shorter for the CS group (20 versus 43 days). The average number of days in the intensive care unit was shorter in the CS group (23 days) compared to the STSG group (37 days).Comparative results between groups are summarized in Figures 4-6.

One patient in the CS group required a cholecystostomy tube for acute cholangitis a week after closure. This was

Table I Characteristics of the eleven patients requiring damage-control laparotomy

\begin{tabular}{|c|c|c|c|c|c|c|c|}
\hline Patient & $\begin{array}{l}\text { Age } \\
\text { (years) }\end{array}$ & Sex & $\begin{array}{l}\text { Hospital } \\
\text { LOS (days) }\end{array}$ & ISS & $\begin{array}{l}\text { Days on a } \\
\text { ventilator }\end{array}$ & $\begin{array}{l}\text { ICU LOS } \\
\text { (days) }\end{array}$ & $\begin{array}{l}\text { Closure } \\
\text { method }\end{array}$ \\
\hline $\mathrm{I}$ & 23 & Male & 30 & 43 & 19 & 22 & Primary \\
\hline 2 & 50 & Male & 21 & 25 & 10 & 13 & Primary \\
\hline 3 & 23 & Male & 9 & 16 & 5 & 6 & Primary \\
\hline 4 & 17 & Male & 22 & 25 & 6 & 8 & Primary \\
\hline 5 & 58 & Male & 9 & 20 & 9 & 9 & Primary ${ }^{\mathrm{a}}$ \\
\hline 6 & 20 & Male & 53 & 34 & 34 & 36 & STSG \\
\hline 7 & 41 & Male & 90 & 34 & 53 & 68 & STSG \\
\hline 8 & 29 & Male & 29 & 34 & 22 & 25 & CS/PADM \\
\hline 9 & 45 & Female & 47 & 38 & 27 & 38 & CS/PADM \\
\hline 10 & 27 & Male & 23 & 27 & 19 & 19 & CS/PADM \\
\hline 11 & 25 & Male & 25 & 25 & 10 & 12 & CS/PADM \\
\hline
\end{tabular}

Note: aPatient died.

Abbreviations: CS, component separation; ICU, intensive care unit; ISS, Injury Severity Score; LOS, length of stay; PADM, porcine-derived acellular dermal matrix; STSG, split-thickness skin graft. 
Table 2 Characteristics of study patients and patients excluded from the study group

\begin{tabular}{lcllccc}
\hline & $\mathbf{n}$ & $\begin{array}{l}\text { Age } \\
\text { (years) }\end{array}$ & $\begin{array}{l}\text { Hospital LOS } \\
\text { (days) }\end{array}$ & ISS & $\begin{array}{l}\text { Days on a } \\
\text { ventilator }\end{array}$ & $\begin{array}{l}\text { ICU LOS } \\
\text { (days) }\end{array}$ \\
\hline $\begin{array}{l}\text { Study group } \\
\text { CS/PADM }\end{array}$ & 4 & $31.5 \pm 9.1$ & $31.0 \pm 11.0$ & $31 \pm 6.1$ & $19.5 \pm 7.1$ & $23.5 \pm 11.0$ \\
$\quad \begin{array}{l}\text { STSG } \\
\begin{array}{l}\text { Excluded } \\
\quad \text { Primary closure }\end{array}\end{array}$ & 2 & $30.5 \pm 14.8$ & $71.5 \pm 26.2$ & $34 \pm 0$ & $43.5 \pm 13.4$ & $37.0 \pm 22.6$ \\
\hline
\end{tabular}

Note: All values are expressed as means \pm standard deviation.

Abbreviations: CS, component separation; ICU, intensive care unit; ISS, Injury Severity Score; LOS, length of stay; PADM, porcine-derived acellular dermal matrix; STSG, split-thickness skin graft.

performed by interventional radiology, and the tube was inserted via the tissue matrix (Figure 7) without complications. There was one enterocutaneous fistula in the STSG group that required multiple visits to the emergency room and readmission to the hospital. All patients were discharged to a rehabilitation center. At the 6-month follow-up, there was no clinical or radiological evidence of hernia in the CS group. There were no complications relating to the feeding tubes.

\section{Discussion}

In DCL, critically ill patients undergo an exploratory laparotomy to control the initial injury, and are managed with an open abdomen while the intensive care team attempts to restore a state of normal physiology. ${ }^{14}$ This is necessitated

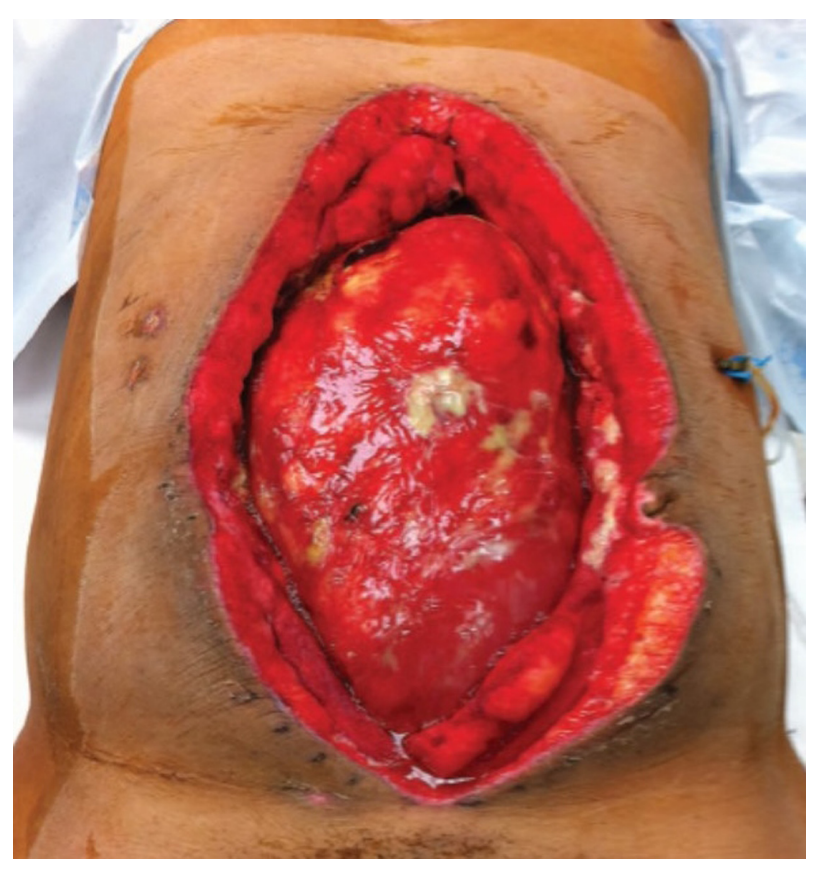

Figure 3 Large abdominal defect prior to closure. In the CS group, the average size of the defect was large $(24 \times 20 \mathrm{~cm})$ and successfully closed using CS reinforced with the non-cross-linked PADM.

Abbreviations: CS, component separation; PADM, porcine-derived acellular dermal matrix. by the fact that these patients often require aggressive fluid resuscitation, which in the setting of a systemic inflammatory response results in significant bowel edema, increasing the likelihood of abdominal compartment syndrome following primary closure. This technique was employed successfully in our study, as early fascial closure was achieved using initial VAC, and once the patient was clinically stable, CS reinforced with a non-cross-linked PADM was performed within 2 weeks of the initial surgery.

An earlier study reported early fascial closure of patients with an open abdomen following DCL, in which VAC was used to facilitate early fascial closure following abdominal trauma. Early definitive fascial closure was achieved in the majority of patients at an average of $9.9 \pm 1.9$ days (range 3-21 days). ${ }^{15}$ In this study, similar early closures averaging $10 \pm 2.8$ days were achieved.

A study by Miller et al evaluated complications associated with open DCL. In their follow-up study of patients requiring closure of an open abdomen, the risk of complications was found to increase with longer times from initial surgery to definitive fascial closure. Based on the results of their study, the authors concluded that delayed fascial closure

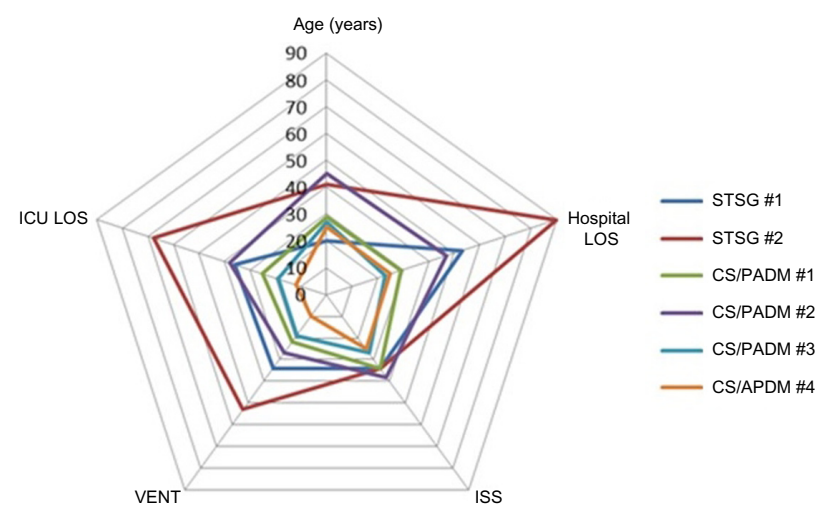

Figure 4 Spider chart displaying outcome measures for patients in both STSG and CS/PADM groups.

Abbreviations: STSG, split-thickness skin graft; CS, component separation; PADM, porcine-derived acellular dermal matrix; ICU, intensive care unit; ISS, Injury Severity Score; LOS, length of stay; VENT, ventilator days. 


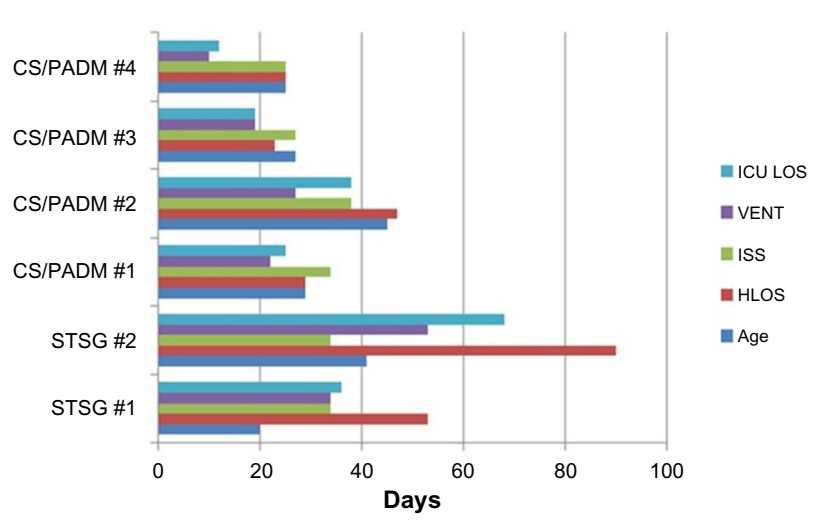

Figure 5 Bar chart displaying STSG and CS-PADM patient-outcome measures. Abbreviations: STSG, split-thickness skin graft; CS, component separation; PADM, porcine-derived acellular dermal matrix; ICU, intensive care unit; ISS, Injury Severity Score; LOS, length of stay; VENT, ventilator days; HLOS, hospital length of stay.

within 8 days was associated with improved outcomes and lower costs. ${ }^{16}$

In 2010, Breuing et al published a landmark paper establishing a grading system to guide surgeons in the assessment of patients with incisional ventral hernia with regard to risk for surgical site occurrences (SSO), especially infection, and to propose evidence-based recommendations regarding the approach to surgical techniques for the repair of incisional hernias, known as the Ventral Hernia Working Group (VHWG) ${ }^{17}$ The recommendations of the VHWG describe evidence-based options for the selection of surgical techniques and appropriate reinforcement material. According to VHWG data, high-risk patients (grade 2), defined as patients who are smokers, obese, diabetics, have chronic obstructive pulmonary disease, or are immunosuppressed, are at an increased risk of surgical site occurrences, which suggests an additive risk of permanent synthetic repair material and a potential advantage for

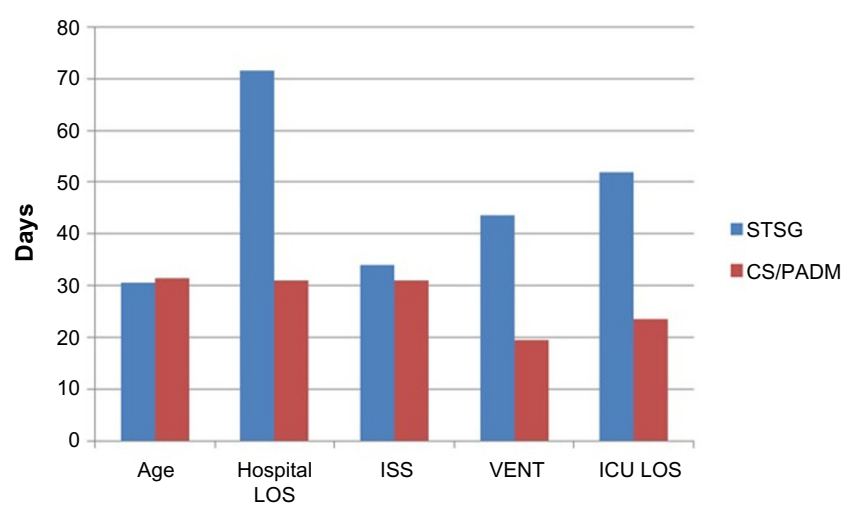

Figure 6 Bar chart comparing outcome measures between the STSG and CS/ PADM groups.

Abbreviations: STSG, split-thickness skin graft; CS, component separation; PADM, porcine-derived acellular dermal matrix; ICU, intensive care unit; ISS, Injury Severity Score; LOS, length of stay; VENT, ventilator days.

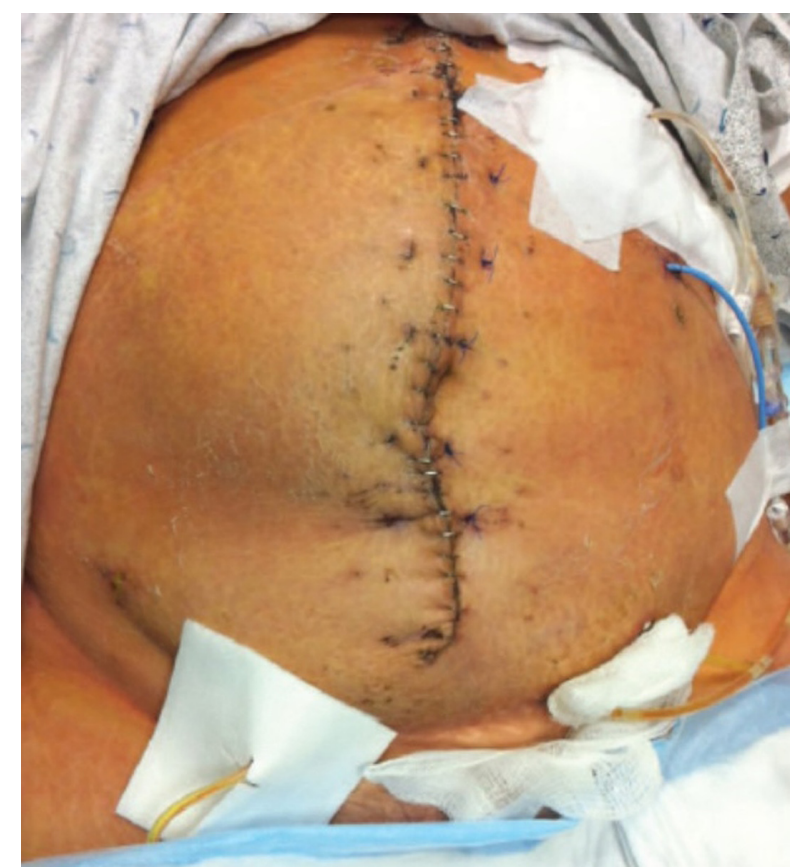

Figure 7 Cholecystostomy tube placement through matrix. One patient in the CS group required a cholecystostomy tube for acute cholangitis a week after closure. This was performed by interventional radiology, and the tube was inserted via the tissue matrix (lower left tube, blue) without complications.

Abbreviation: CS, component separation.

appropriate biologic reinforcement. ${ }^{18-21}$ Our present study displays the potential benefit of using biologic reinforcement, as patients closed with PADM reinforcement had shorter hospital LOS, fewer days on a ventilator when compared to STSG closure, and no evidence of hernias at the 6-month follow-up.

Due to the small patient population, no formal cost analysis was performed in the present study; however, this does not negate the potential cost advantage of our findings. For example, although the patients showed a similar severity of injury between the CS and STSG groups, the CS group had shorter total hospital LOS and days on the ventilator than the STSG group. This will presumably result in a decrease in resource consumption and therefore lower costs. Our current payment system allows for a set reimbursement rate for the diagnosis related groups. Clearly, these cases fall outside the range for diagnosis related groups; therefore, the hospital would be at reduced risk for costs incurred beyond the normal LOS. Since only one surgery is required, and readmissions for skin removal and hernia repair were not necessary in the group treated with CS reinforced with non-cross-linked PADM, the CS approach would potentially further decrease the overhead costs for the hospital.

As a retrospective study with a very small number of patients from one center, these results must be seen as 
preliminary and cannot be easily generalized. Nevertheless, the results indicate the potential benefits of the use of non-cross-linked PADM for early abdominal closure using CS in trauma patients following DCL.

\section{Conclusion}

The present findings suggest that early abdominal closure using CS with a non-cross-linked PADM is safe and effective. This technique appears to be potentially costeffective, since only one operation is required and there is a decrease in hospital LOS and ventilator days. To evaluate the potential of this technique fully in terms of safety, clinical benefit, and cost-effectiveness, future larger-scale studies are needed. We believe the data from our study serve as an important starting point.

\section{Acknowledgments}

The authors received editorial support in the preparation of this manuscript funded by LifeCell Corporation. Pieter van Bokhoven, PhD, from Excerpta Medica, Bridgewater, NJ, and Jim Wood from Peloton Advantage, LLC, Parsippany, NJ, provided editorial assistance. The authors are fully responsible for content and editorial decisions.

\section{Disclosure}

The authors received no honoraria or other forms of compensation related to the development of this manuscript, and declare no conflicts of interest.

\section{References}

1. Asensio JA, McDuffie L, Petrone P, et al. Reliable variables in the exsanguinated patient which indicate damage control and predict outcome. Am J Surg. 2001;182(6):743-751.

2. Burch JM, Ortiz VB, Richardson RJ, Martin RR, Mattox KL, Jordan GL Jr. Abbreviated laparotomy and planned reoperation for critically injured patients. Ann Surg. 1992;215(5):476-483; discussion 483-484.

3. Germanos S, Gourgiotis S, Villias C, Bertucci M, Dimopoulos N, Salemis N. Damage control surgery in the abdomen: an approach for the management of severe injured patients. Int J Surg. 2008;6(3):246-252.

4. Rotondo MF, Schwab CW, McGonigal MD, et al. 'Damage control': an approach for improved survival in exsanguinating penetrating abdominal injury. J Trauma. 1993;35(3):375-382; discussion 382-383.

Open Access Surgery

\section{Publish your work in this journal}

Open Access Surgery is an international, peer-reviewed, open access journal that focuses on all aspects of surgical procedures and interventions. Patient care around the peri-operative period and patient outcomes post surgery are key topics. All grades of surgery from minor cosmetic interventions to major surgical procedures are covered. Novel techniques
5. Cohen M, Morales R Jr, Fildes J, Barrett J. Staged reconstruction after gunshot wounds to the abdomen. Plast Reconstr Surg. 2001;108(1): 83-92.

6. Fabian TC. Damage control in trauma: laparotomy wound management acute to chronic. Surg Clin North Am. 2007;87(1):73-93.

7. Miller PR, Thompson JT, Faler BJ, Meredith JW, Chang MC. Late fascial closure in lieu of ventral hernia: the next step in open abdomen management. J Trauma. 2002;53(5):843-849.

8. Miller PR, Meredith JW, Johnson JC, Chang MC. Prospective evaluation of vacuum-assisted fascial closure after open abdomen: planned ventral hernia rate is substantially reduced. Ann Surg. 2004;239(5):608-614.

9. Tremblay LN, Feliciano DV, Schimdt J, et al. Skin only or silo closure in the critically ill patient with an open abdomen. $\mathrm{Am} \mathrm{J}$ Surg. 2001;182(6):670-675.

10. Howdieshell TR, Proctor CD, Sternberg E, Cué JI, Mondy JS, Hawkins ML. Temporary abdominal closure followed by definitive abdominal wall reconstruction of the open abdomen. Am J Surg. 2004;188(3):301-306.

11. Mathes SJ, Steinwald PM, Foster RD, Hoffman WY, Anthony JP. Complex abdominal wall reconstruction: a comparison of flap and mesh closure. Ann Surg. 2001;232(4):586-596.

12. Silverman RP, Singh NK, Li EN, et al. Restoring abdominal wall integrity in contaminated tissue-deficient wounds using autologous fascia grafts. Plast Reconstr Surg. 2004;113(2):673-675.

13. Itani KM, Rosen M, Vargo D, Awad SS, Denoto G 3rd, Butler CE. Prospective study of single-stage repair of contaminated hernia using a biologic porcine tissue matrix: the RICH study. Surgery. 2012;152(3):498-505.

14. Hatch Q, Osterhout L, Ashraf A, et al. Current use of damage-control laparotomy, closure rates, and predictors of early fascial closure at the first take-back. J Trauma. 2011;70(6):1429-1436.

15. Garner GB, Ware DN, Cocanour CS, et al. Vacuum-assisted wound closure provides early fascial reapproximation in trauma patients with open abdomens. Am J Surg. 2001;182(6):630-638.

16. Miller RS, Morris JA Jr, Diaz JJ, Herring MB, May AK. Complications after 344 damage-control open celiotomies. J Trauma. 2005;59(6): 1365-1374.

17. Breuing K, Butler CE, Ferzoco S, et al. Incisional ventral hernias: review of the literature and recommendations regarding the grading and technique of repair. Surgery. 2010;148(3):544-558.

18. Dunne JR, Malone DL, Tracy JK, Napolitano LM. Abdominal wall hernias: risk factors for infection and resource utilization. J Surg Res. 2003;111(1):78-84.

19. Finan KR, Vick CC, Kiefe CI, Neumayer L, Hawn MT. Predictors of wound infection in ventral hernia repair. Am J Surg. 2005;190(5): 676-681.

20. Pessaux P, Lermite E, Blezel E, et al. Predictive risk score for infection after inguinal hernia repair. Am J Surg. 2006;192(2):165-171.

21. Petersen S, Henke G, Freitag M, Faulhaber A, Ludwig K. Deep prosthesis infection in incisional hernia repair: predictive factors and clinical outcome. Eur J Surg. 2001;167(6):453-457.

and the utilization of new instruments and materials, including implants and prostheses that optimize outcomes constitute major areas of interest. The manuscript management system is completely online and includes a very quick and fair peer-review system. Visit http://www.dovepress.com/ testimonials.php to read real quotes from published authors. 